\title{
Entre cativeiros: africanos livres na formação do Estado imperial e na economia-mundo oitocentista
}

\author{
Marcelo Ferraro* \\ Universidade de São Paulo \\ São Paulo - São Paulo - Brasil
}

Resenha de: MAMIGONIAN, Beatriz. Africanos Livres: a abolição do tráfico de escravos no Brasil. São Paulo: Companhia das Letras, 2017. 632 p.

* Marcelo Ferraro é formado em Direito (2009) e História (2013) pela Universidade de São Paulo, e possui Mestrado em História (2017) pela mesma instituição. E-mail: marcelo178@gmail.com. 
A publicação de Africanos Livres oferece ao público em geral e, especialmente ao campo historiográfico brasileiro, uma referência incontornável sobre temas como escravidão e abolição do tráfico no Império do Brasil. Desde o doutorado desenvolvido na Universidade de Waterloo, no Canadá, a obra é o resultado de mais de vinte anos de pesquisa e da análise de uma vasta documentação. A pesquisa original se referia aos africanos traficados ilegalmente que tiveram tal condição reconhecida pelo Estado brasileiro, mas a presente obra abarca aqueles escravizados ilegalmente com a conivência das autoridades do país. Desse modo, Beatriz Mamigonian narra uma história da abolição do tráfico no Brasil a partir da experiência dos africanos contrabandeados entre as décadas de 1820 e 1850.

Ainda na introdução, a autora reitera seu posicionamento entre os historiadores da escravidão enfatizando o papel dos sujeitos históricos, com destaque aqui para os africanos livres. Hegemônica no campo acadêmico desde meados da década 1980, a agenda da agência escrava ofereceu ganhos conceituais e políticos para a compreensão da escravidão e do racismo no Brasil. No entanto, o livro busca incorporar dinâmicas mais amplas da política e das relações internacionais, seguindo o movimento recente de historiadores do campo. Cabe ressaltar que essa história da escravidão "vista de baixo" inspirou-se nos estudos de Edward Thompson sobre as transformações na sociedade inglesa à época da Revolução Industrial. Marxista heterodoxo, Thompson criticava e recusava a imposição de conceitos abstratos às experiências de indivíduos e suas percepções. Contudo, as condicionantes e amarras do capitalismo sempre estiveram presentes em suas análises. Desse modo, a reorientação recente dos estudos brasileiros sobre a escravidão, tal como se vê nessa pesquisa, aponta para uma bem-vinda conciliação com seu paradigma original, embora a dinâmica da economia global permaneça obliterada na narrativa de Mamigonian.

Os capítulos acompanham as trajetórias dos africanos livres desde o início do século XIX, quando a categoria foi criada em resultado das primeiras leis e tratados que limitavam ou condenavam o tráfico, até a década de 1880, momento em que a vertente mais radical do movimento abolicionista brasileiro adotou a estratégia de reconhecer todos 
os africanos escravizados ilegalmente no país como africanos livres. Ordenada cronologicamente, a narrativa parte do caso da Escuna Emília e dos africanos nela contrabandeados ao norte da linha do Equador em 1821, violando os tratados firmados entre a Grã Bretanha e a diplomacia de D. João VI. Os dois primeiros capítulos avançam até a independência de 1822 e o reinado de D. Pedro I, em um encadeamento não linear, mas coerente, entre o projeto antiescravista de José Bonifácio na Assembleia Constituinte, os Tratados firmados com a Grã Bretanha em 1826 e a promulgação da Lei de 7 de novembro de 1831. Conhecida no senso comum como uma "lei para inglês ver", essa lei foi efetivamente aplicada nos primeiros anos, caindo em conveniente desuso em meados da década de 1830, a partir da convergência entre a campanha dos cafeicultores escravistas e os membros do Partido da Ordem. A política conservadora em prol do tráfico não se concretizou na revogação da lei, mas no aceno a escravistas e traficantes no sentido de que o Estado não adotaria medidas no sentido do combate do contrabando. A narrativa descreve então o acirramento das relações entre Brasil e Grã Bretanha, tanto no cenário que levou à promulgação da Lei Eusébio de Queiroz, em 1850, quanto no dos embates entre o governo imperial e o embaixador britânico William Christie, que culminou com a ruptura das relações entre os países na década de 1860. Em ambos os casos, a autora propõe um argumento semelhante, segundo o qual os africanos livres teriam contribuído para o afloramento das tensões entre os países, reivindicando seus direitos na esteira das crises políticas instauradas. A despeito da emancipação definitiva dos africanos livres em 1864, os capítulos finais avançam até a década de 1880, revelando a precariedade da liberdade desses africanos, assim como seu papel nas estratégias do movimento abolicionista durante a crise que levou à derrocada do cativeiro em 1888.

Os sujeitos históricos ilegalmente escravizados são personagens em todos os capítulos. Sob a promessa do retorno à África ou da sua incorporação à sociedade brasileira, os africanos livres foram submetidos a trabalhos compulsórios, fosse em órgãos públicos ou nas casas e fazendas de particulares. Em condições próximas ao cativeiro e convivendo com escravos, viveram sob a insegurança jurídica de sua condição e 
a falta de clareza sobre os prazos da tutela. Mais do que um eufemismo, sua definição como "livres" carregava um componente ideológico típico do discurso escravista (e posteriormente do racismo) brasileiro. No entanto, a consciência da ambiguidade de sua posição social os tornava potencialmente disruptivos tanto para os governos quanto para a ordem social escravista. Ao acionarem a embaixada britânica, associações abolicionistas e o judiciário, eles constrangiam autoridades do Estado, inclusive diante da comunidade internacional. Por sua vez, a proximidade com os escravos poderia estimular sua resistência, especialmente daqueles contrabandeados e escravizados ilegalmente.

Ao descrever as experiências de indivíduos submetidos ao contrabando, ao cativeiro ilegal e a trabalhos forçados, a obra resgata a memória silenciada de opressões do passado. A despeito da importância política dessa escolha, nem todas as trajetórias correspondem ao papel decisivo que lhes é imputado em cada capítulo. A autora sustenta que o protagonismo dos africanos livres deve ser compreendido a partir de um jogo de escalas que revela novas dinâmicas de três eixos temáticos: as consequências jurídicas da Lei de 1831, a experiência do trabalho no Atlântico oitocentista e a conjuntura que levou à abolição do tráfico. A escala da vivência dos africanos livres de fato materializa e humaniza a experiência da ilegalidade que marcou a formação da sociedade brasileira e do Estado nacional entre as décadas de 1820 e 1840, assim como o cenário de mobilização política das últimas duas décadas da escravidão no país. No entanto, a autora narra a agência dos africanos livres nos primeiros e nos últimos capítulos em paralelo com eventos mais amplos da política nacional e das relações exteriores, como se apenas sugerisse tênues relações de causalidade.

O capítulo sexto, por sua vez, consiste na empreitada mais ambiciosa do referido jogo de escalas, tanto metodológica quanto historiograficamente, sendo o ponto mais polêmico do livro. Nele Mamizonian apresenta o cenário que levou à promulgação da Lei Eusébio de Queiroz, destacando atores institucionais como o Ministro Britânico Palmerston, o embaixador James Hudson e os membros do gabinete conservador no poder à época. Juntam-se a eles a conspiração de escravos descoberta em 1848, apontada pelo historiador Robert Sle- 
nes como influente nos temores que levaram as autoridades a acatarem a agenda da abolição do tráfico. ${ }^{1}$ A contribuição de Mamigonian está em apontar a participação de políticos liberais nos conflitos que levaram ao fim do tráfico, com destaque para duas instituições que militavam contra a conivência das autoridades com o contrabando: o periódico "O Philantropo" e a "Sociedade contra o Tráfico de Africanos e Promotora da Colonização e da Civilização dos Indígenas”. O capítulo atinge o clímax nas últimas páginas, quando a historiadora sugere a existência de uma articulação política que interligaria o governo britânico e o embaixador Hudson a políticos do Partido Liberal, que teriam se valido das duas instituições mencionadas e, possivelmente, até mesmo de um estímulo à articulação dos escravos conspirados. Mamigonian caminha no mesmo sentido do estudo recente de Angela Alonso sobre o movimento abolicionista, enfatizando o papel da sociedade civil, da opinião pública e da militância durante o Império. ${ }^{2}$ Segundo a autora, o discurso de Eusébio de Queiroz, em 1852, mais do que defender o governo conservador à época da abolição do tráfico, serviu à construção de uma memória seletiva que apagou a articulação entre abolicionistas ingleses e brasileiros, bem como a estratégia de incitar escravos e africanos liores como meio para desestabilizar a política em prol do contrabando.

A hipótese demanda mais estudos e dados, especialmente no tocante ao último elo - entre abolicionistas e escravos -, como reconhece a própria autora. A argumentação inevitavelmente abre flancos para críticas. A título de exemplo, a leitura permite uma interpretação equivocada das agendas dos partidos, como se houvesse uma divisão clara entre conservadores-escravistas e liberais-abolicionistas. Em segundo

1 Ver SLENES, Robert. "A árvore de Nsanda transplantada: Cultos Kongo de aflição e identidade escrava no sudeste brasileiro (século XIX)" In: LIBBY, Douglas Cole; FURTADO, Júnia (orgs.) Trabalho livre, trabalho escravo: Brasil e Europa, séculos XVIII e XIX. São Paulo: Anablume, 2006, pp. 273-314;

2 Ver ALONSO, Angela. Flores, Votos e Balas: O Movimento Abolicionista Brasileiro, 1868-1888. São Paulo: Companhia das Letras, 2016. O diálogo entre as perspectivas teóricas de ambas as autoras contribuiria para o campo, mas não consta a referência na bibliografia de Mamigonian. 
lugar, a argumentação reproduz a autoimagem humanitária do abolicionismo britânico, como fazem os estudos do historiador Seymour Drescher, perdendo-se de vista seu caráter ideológico como instrumento imperialista. ${ }^{3}$ Em uma breve passagem do quinto capítulo, a historiadora chega a sugerir um enquadramento mais amplo, em que o debate acerca do tráfico e dos africanos livres cumpriria diferentes funções nas duas margens do Atlântico, relacionando-se, de um lado, aos riscos imanentes à sociedade escravista brasileira, e de outro, à ideologia da "missão civilizadora" que permitiria aos britânicos intervirem no território africano. A curta passagem mereceria uma análise mais aprofundada e deixa de repercutir no capítulo sexto. De todo modo, trata-se do melhor exercício do método de escalas proposto pela historiadora, assim como de sua defesa do papel dos sujeitos históricos no processo de abolição do tráfico - embora apresente mais provas da agência dos abolicionistas do que dos africanos livres. A despeito das lacunas, a contribuição para o debate historiográfico atesta a importância da pesquisa.

A respeito do enquadramento teórico, o estudo tem o mérito de propor um jogo de escalas que integraria sujeitos às camadas da política e da economia, superando as fronteiras nacionais. No entanto, a narrativa se limita a quatro níveis de análise nem sempre articulados: a exploração e a resistência de africanos livres; instituições da sociedade civil, como associações e veículos da imprensa (essencialmente "O Philantropo" e a "Sociedade contra o Tráfico", presentes em poucos capítulos); a dinâmica da alta política imperial; e a pressão diplomática britânica. Além disso, as escalas tendem a recair no individualismo metodológico quando se reduzem aos agentes que as compõem, sejam os africanos, os políticos ou os abolicionistas. O estudo se beneficiaria da incorporação de dinâmicas geopolíticas e econômicas globais, ou ao menos atlânticas. No que diz respeito à década de 1830, Mamigonian descreve a guinada política representada pelo Regresso Con-

3 Ver DRESGHER, Seymour. Abolição: uma história da escravidão e do antiescravismo. São Paulo: Editora Unesp, 2011 
servador e sua nova agenda no tocante ao tráfico e aos africanos livres. No entanto, embora mencione o papel da campanha dos produtores do Vale do Paraíba na campanha pela revogação da Lei de 1831 e sua articulação com os políticos do Partido da Ordem, a historiadora não atenta para as demandas econômicas internacionais a partir da abertura dos mercados estadunidenses para o café brasileiro. Mais relevante ainda seria a percepção do cenário atlântico nas décadas de 1850 e 1860, quando ocorreram as emancipações dos africanos livres - primeiramente daqueles concedidos a particulares (1853) e posteriormente daqueles mantidos como prestadores de serviços forçados ao Estado (1864). A primeira emancipação foi associada por Mamigonian à crescente demanda dos africanos livres após a crise política que levou à abolição do tráfico em 1850, devido à consciência de um novo horizonte de oportunidade. Por sua vez, a emancipação definitiva na década de 1860 foi interpretada como resultante da pressão abolicionista de políticos liberais e do embaixador William Christie. No entanto, o horizonte do cativeiro se estreitara naquela década por causa da Guerra Civil nos Estados Unidos, que legou ao Brasil a condição de único Estado nacional escravista das Américas. O mesmo contexto que provocou um racha entre a elite política e o declínio do consenso que sustentava a política da escravidão contribuiu para a percepção dos africanos livres como elementos disruptivos na ordem escravista. $\mathrm{O}$ jogo de escalas proposto por Mamigonian perde fôlego para além das fronteiras nacionais, reduzindo-se às pressões britânicas e aos discursos e ações de políticos e abolicionistas e às suas influências unilaterais na política e na sociedade brasileiras.

Sobre a dimensão econômica global de seu jogo de escalas, a historiadora propõe uma reflexão a respeito do mundo do trabalho no século XIX, questionando a falsa antítese entre escravidão e trabalho "livre". A exploração de africanos livres junto a escravos, prisioneiros e indígenas demonstrou tanto a precariedade da liberdade na era da abolição, quanto a multiplicidade de formas de trabalho compulsório no período. Ao se aproximar do tema do trabalho, Mamigonian abdicou de um debate sobre o capitalismo oitocentista. Na introdução do livro, esboçou tal movimento ao apresentar a dinâmica da escravidão 
como radicalmente nova, tendo em vista a expansão de zonas produtoras de artigos tropicais para o mercado internacional, em referência aos estudos de Dale Tomich. Mas o diálogo com a agenda de estudos sobre capitalismo e escravidão não encontrou eco nos capítulos seguintes - seria importante fazê-lo inclusive no capítulo sexto. Do mesmo modo, os historiadores que têm levado adiante a perspectiva de Tomich e defendido uma abordagem sistêmica da escravidão no século XIX não figuram nos parágrafos ou notas. ${ }^{4} \mathrm{O}$ mesmo valeria para $\mathrm{o}$ diálogo com os estudos que tratam da diversidade de formas de trabalho na economia global, ou para a historiografia que cruza dinâmicas mais amplas com base em biografias - referência mais próxima de seu posicionamento no campo. ${ }^{5}$ A proposta metodológica de Mamigonian

4 O diálogo proposto se refere aos estudos de Dale Tomich e o conceito da "Segunda Escravidão", mas não se estende aos historiadores brasileiros que vem desenvolvendo pesquisas no mesmo sentido nas últimas décadas. Ver TOMICH, Dale. Pelo prisma da escravidão: trabalho, capital e economia mundial. Trad. Port. São Paulo: EDUSP, 2011. E sobre a referida omissão ver BLACKBURN, Robin Blackburn, The American Crucible. Slavery, Emancipation and Human Rights, Londres, Verso, 2011; PIQUERAS, José A. (ed.), Trabajo Libre y Coactivo en Sociedades de Plantación, Madri, Siglo XXI, 2009; SCHMIDT-NOWARA, Christopher. Empire and Antislavery: Spain, Cuba and Puerto Rico, 1833 - 1874, Pittsburgh, University of Pittsburgh Press, 1999; ZEUSKE, Michael. "Comparing or interlinking? Economic comparisons of early nineteenth-century slave systems in the Americas in historical perspective", in Enrico dal Lago \& Constantina Katsari (eds.), Slave Systems. Ancient and Modern, Cambridge, Cambridge University Press, 2008, p. 148-183; KAYE, Anthony, "The Second Slavery: Modernity in the Nineteenth-Century South and the Atlantic World", fornal of Southern History, vol. 73, n. 3, August 2009, p. 627-50; BERBEL, M., MARQUESE, R. B. e PARRON, T. Escravidão e política: Brasil e Cuba, 1790-1850. São Paulo: Hucitec, 2011; DAL LAGO, Enrico, American Slavery, Atlantic Slavery, and Beyond. The U.S. "Peculiar Institution" in International Perspective, Boulder, Paradigm Publishers, 2012; e MARQUESE, R. B.; SALLES, (orgs.). Escravidão e Capitalismo Histórico no Século XIX. Rio de Janeiro: Civilização Brasileira, 2016.

5 Para as primeiras abordagens, VAN DER LINDEN, Marcel. Trabalhadores do Mundo. Ensaios para uma história global do trabalho (trad.port.) Campinas: Ed. Unicamp, 2013; e LINEBAUGH, Peter \& REDIKER, Marcus. The Many-Headed Hydra. Sailors, Slaves, Commoners, and the Hidden History of the Revolutionary Atlantic. Boston: Beacon Press, 2000. Sobre a historiografia baseada em biografias e sujeitos históricos, SCOTT, Rebecca; HÉBRARD, Jean. Provas de Liberdade: Uma odisseia atlântica na era da emancipação. São Paulo: Unicamp, 2014. REIS, João; GOMES, Flávio; CARVALHO, Marcus. O Alufá Rufino. Tráfico, escravidão e liberdade no Atlântico Negro (1822-1853). São Paulo: Companhia das Letras, 2010. 
poderia se valer da incorporação ou da crítica a outras matrizes teóricas, de modo a esclarecer suas premissas e vantagens de seu jogo de escalas, cujos resultados efetivos oscilaram entre os capítulos. ${ }^{6}$

No epílogo, a historiadora apresenta em retrospecto as contribuições da pesquisa, destacando o desafio à memória oficial sobre as leis antitráfico de 1831 e 1850. Na contramão da narrativa construída por Eusébio de Queiroz, a primeira lei não teria sido legada ao esquecimento absoluto, e a segunda não seria o resultado do protagonismo patriótico dos saquaremas contra a Grã-Bretanha. Tampouco haveria uma linha progressiva e gradual entre a abolição do tráfico e a da escravidão. Mamigonian retoma com maior contundência seus argumentos referentes à resistência e articulação entre abolicionistas, africanos livres e escravos, enfatizando a imprevisibilidade de cada contexto e a importância de seu protagonismo. Para além dos ganhos historiográficos, a obra se destaca pelo engajamento político no presente. Acessível ao público em geral, o livro segue a tônica de estudos recentes ao refutar a memória oficial brasileira, marcada por esquecimentos seletivos e interessados, que negam a relevância social dos marginalizados e as estruturas políticas e econômicas que os marginalizaram. Em tempos de precarização das relações de trabalho e de discursos negacionistas do passado e do presente racial brasileiro, a lembrança dos africanos

6 A obra se beneficiaria do diálogo com os estudos recentes que vêm analisando o tráfico negreiro e a escravidão à luz da dinâmica da economia global no cenário da Revolução Industrial e da ordem geopolítica sob a hegemonia da Grã Bretanha, como MARQUES, Leonardo. The United States and the Transatlantic Slave Trade to the Americas, 1776-1867. New Haven; London: Yale University Press, 2016; e PARRON, Tâmis. A política da escravidão na era da liberdade: Estados Unidos, Brasil e Cuba, 17871846. Tese. Universidade de São Paulo, 2015. O mesmo pode ser dito no tocante à experiência do direito e da escravidão no Atlântico oitocentista com relação ao estudo de, Waldomiro da Silva Junior, Entre a escrita e a prática: direito e escravidão no Brasil e em Cuba, c. 1760-1871. Tese. Universidade de São Paulo em 2015. Por fim, embora se posicione entre os historiadores que defendem a agenda da agência escrava, a pesquisa deixou de dialogar com estudos como o de Maria Helena Machado, O Plano e o Pânico: os movimentos sociais na década da abolição. São Paulo: Edusp, 2010. Seria igualmente relevante a incorporação do estudo sobre a precariedade da liberdade de Henrique Espada Lima, "Sob o domínio da precariedade: escravidão e os significados da liberdade de trabalho no século XIX”. Topoi (Rio de Janeiro), v. 6, n. 11, Julho-dezembro de 2005, pp. 289-326. 
livres incomoda posições de privilégio e de poder ao denunciar o que se convencionou legar ao silêncio.

Recebido: 25/11/2017 - Aprovado: 05/12/2017 